\title{
Geometrical Analysis of Warp Knit Auxetic Fabrics
}

\section{Samuel C Ugbolue ${ }^{1 *}$, Olena Kyzymchuk ${ }^{2}$ and Yong K Kim ${ }^{1}$}

${ }^{1}$ Department of Bioengineering, University of Massachusetts, Dartmouth, USA

${ }^{2}$ Kyiv National University of Technology and Design, Ukraine

\begin{abstract}
Despite considerable interests that have been shown on the formation, properties and characteristics of auxetic knit structures there remains a dearth of information about the fundamental geometrical analytics of warp knit auxetic fabrics. This paper examines the geometrical model of auxetic warp knit structure and validates its characteristics with data obtained from experimental analysis of nine recently produced warp knit auxetic fabrics.
\end{abstract}

Keywords: Auxetic structure; In-laying yarn; Fabric geometry; Preknitting

\section{Introduction}

In recent years, considerable interests have been shown on the formation, properties and characteristics of auxetic knit structures [17]. Auxetic structures can enable an article to exhibit an expansion in a lateral direction, upon subjecting the article to a longitudinal stress or strain. Conversely, auxetic structures also exhibit a contraction in the lateral direction upon subjecting such an article to longitudinal compression. Such materials are understood to exhibit a negative Poisson's ratio. However, very limited studies have been produced on the fundamental geometrical analytics of warp knit auxetic fabrics. It is recognized that the geometry of fabrics has significant effects on their behavior. Hence Ugbolue et al. [4] focused on the geometry and structural properties of warp knit auxetic fabrics in one of their papers. Generally, the complexity of warp knitted structures have posed major challenges to researchers but several studies on the geometry of warp knitted structures have been published in the literature [8]. Early attempts on the study of the subject were experimental studies in which the dimensional properties of the warp-knitted structure were investigated by Fletcher and Roberts $[9,10]$ and by Stimmel $[11,12]$. Later, a geometrical model for warp-knitted structures was developed by Allison [13] and then Grosberg [14] presented a full picture of the warp-knitted-loop configuration for two-bar warp-knitted fabrics. Subsequently, Grosberg [15] improved the previously suggested geometrical model wherein he assumed that the root end of the loop laid at the widest section of the previous loop and the underlap was part of a circle. The third geometrical model was developed by Shinn and El-Araf [16]. Wheatley [17] and Jacobsen [18] also proposed some geometrical loop models for warp-knitted structures produced from wool yarns. These researchers were keenly interested in finding some relationships between fabric parameters and fabric dimensions that were akin to those found for weft-knitted structures in order to facilitate some production calculations in industrial settings and encourage efforts in predicting some fabric properties after [19]. Our thrust in prior research combined our knowledge of geometry and fabric structural characteristics to engineer auxetic textiles and to determine the properties of such auxetic textile fabrics. Auxetic warp knit fabrics have great potentials in many areas of application such as protective clothing, blast resistant uniforms and other industrial textiles.

Our continued efforts to produce auxetic knit structures from non-auxetic yarns are described here. Specifically, this paper examines our geometrical model of auxetic warp knit structure and validates its characteristics with data obtained from experimental analysis of nine recently produced warp knit auxetic fabrics.

\section{Theoretical analysis}

A typical warp knit structure under strain is shown in Figure 1. The length of interlooping repeat that is formed by alternation of tricot $\left(n_{t}\right)$ and chain $\left(\mathrm{n}_{\mathrm{c}}\right)$ courses during drawing off at knitting machine (Figure 1) could be calculated as follows:

$$
L_{R}^{s}=2 n_{t} B_{t} \max +2 n_{c} B_{c} \max
$$

Where $\mathrm{B}_{\mathrm{t} \text { max }}$ and $\mathrm{B}_{\mathrm{c} \max }$ are maximum height of tricot and chain courses under a strain respectively $\mathrm{mm}$ :

$$
B_{t \max }=\frac{l_{t}-2.5 \pi d_{\min }}{3} \text { and } B_{c \max }=\frac{l_{c}-(3+2.5 \pi) d_{\min }}{3}
$$

Where lt and lc are loop length of tricot and chain, mm respectively, $\mathrm{dmin}$ is the diameter of yarn under strain, $\mathrm{mm}$;

After relaxation as shown in Figure 2,

$L_{R}=a_{1}+h$

Where $\mathrm{a}_{1}$ is length of vertical rib, $\mathrm{mm}$

$\mathrm{h}$ is distance between two vertical ribs in wale wise direction, $\mathrm{mm}$.

It is obviously clear that:

$a_{1}=\left(n_{t}-1\right) \mathrm{B}_{\mathrm{t}}$

Where $B_{t}$ is height of tricot course mm,

$\mathrm{B}_{\mathrm{t}}=0.25 l_{t}-0.03 \sqrt{T}$

Where $\mathrm{T}$ is the linear density of yarn, tex

For conventional warp knit structure with hexagonal net (Figure 2a) distance $\mathrm{h}$ is calculated by:

$$
h=\left(n_{t}-1\right) B_{t}+2\left(B_{t}+n_{c} B_{c}\right) \cos \alpha
$$

Where $\mathrm{B}_{\mathrm{c}}$ - height of chain courses, $\mathrm{mm}$

$$
B_{c}=\frac{l_{c}-3(\pi-1) d}{3}
$$

*Corresponding author: Ugbolue SC, Lecturer, Department of Bioengineering University of Massachusetts, Dartmouth, USA, E-mail: sugbolue@umassd.edu

Received May 04, 2015; Accepted May 14, 2015; Published July 15, 2015

Citation: Ugbolue SC, Kyzymchuk O, Kim YK T(2015) Geometrical Analysis of Warp Knit Auxetic Fabrics. J Textile Sci Eng 5: 201. doi:10.4172/21658064.1000201

Copyright: @ 2015 Ugbolue SC, et al. This is an open-access article distributed under the terms of the Creative Commons Attribution License, which permits unrestricted use, distribution, and reproduction in any medium, provided the original author and source are credited. 


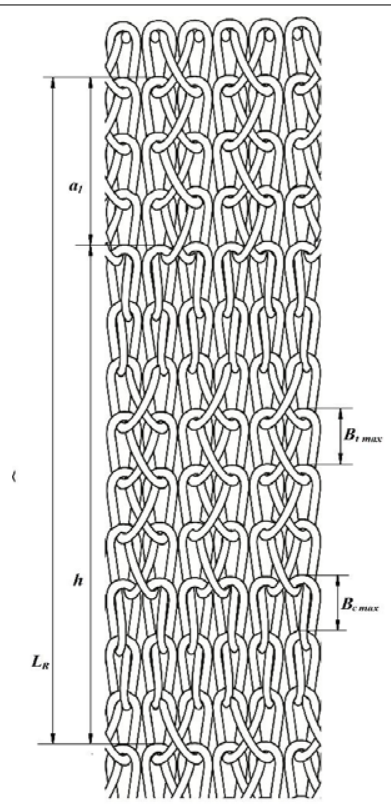

Figure 1: Warp knit structure under strain

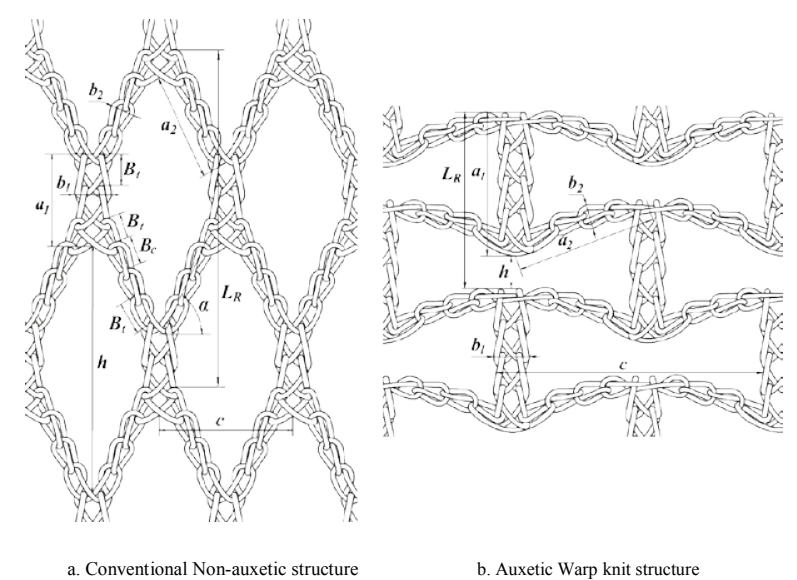

Figure 2: Warp knit structure with hexagonal net.

Where $\mathrm{d}$ is the diameter of yarn, $\mathrm{mm}$, and $\alpha$ is angle between diagonal rib and horizontal.

The geometrical model depicted in Figure $2 \mathrm{~b}$ shows the configuration of our Auxetic warp knit structure. Thus, the length of interlooping repeat of conventional warp knit structure is given by:

$L_{R}=a_{1}+h=2\left(n_{t}-1\right) B_{t}+2\left(B_{t}+n_{c} B_{c}\right) \cos \alpha$

Also, Figure $2 \mathrm{~b}$ depicts the auxetic warp knit geometrical structure with hexagonal mesh and its auxetic configuration is realized when the following condition is satisfied:

$$
h<a_{1}-2 b_{2} \text { or } h<\left(\mathrm{n}_{t}-1\right) B_{t}-2 b_{2}
$$

Therefore, the length of interlooping repeat of auxetic warp knit structure is:

$$
L_{R}=\left(n_{t}-1\right) B_{t}+h \text { or } L_{R}<2\left(n_{t}-1\right) B_{t}-2 b_{2}
$$

As was proposed by Ugbolue et al. [3,4] to achieve auxetic property, it is required to employ a high elastic yarn in the basic filet warp knit structure. This yarn must to be placed between the stitch wale in the knitting direction to insure that the fabric structure will retain necessary configuration after relaxation. The filling yarn makes contact with the ground yarn just at the vertical ribs from tricot courses and is inlaid between vertical and diagonal ribs inside the hole at the other part of net. Also in their previous paper, Kyzymchuk and Ugbolue [20] affirmed that the positioning of inlaid yarns in filet warp knit structure is determined by the amount and direction of inlaying and ground guide bars' shifting behind the needles as well as disposition of guide bars with ground and filling yarns. It was determined that the in-laid yarn could be positioned inside the structure in one, two, three or five courses of vertical rib and might also be laid between the tricot's junctures from different ground yarns or wrapped junctures from one or both ground guide bars. Thus, two variants of inlaid yarn positioning are showed at Figure 3.

Consequently, the length of interloping repeat of such structure could be calculated as:

$$
L_{R}=L_{i}+L_{f}
$$

Where $L_{i}$ is length of elastomeric yarn that is fixed in the knitted structure,

$L_{f}$ is length of elastomeric yarn that is not fixed in the knitted structure

For our modelling we adopt the following assumptions:

(i) The relaxation of elastomeric yarn, that is fixed in the structure, is insignificant and does not affect the size and shape of the loops;

(ii) A full relaxation of elastomeric yarn occurs only in the area where the yarn is not fixed in the structure.

Thus, lengths of elastomeric yarn that are fixed in knitted structure are determined as follows:

- $\quad$ during drawing off at knitting machine:

$$
\begin{aligned}
& L_{i}^{s}=(i-0.5) B_{t \max } \\
& \text { - } \quad \text { after relaxation: }
\end{aligned}
$$

$L_{i}=(i-0.5) B_{t}$

Where $i$ is the number of tricot courses in which the elastomeric yarn is fixed.
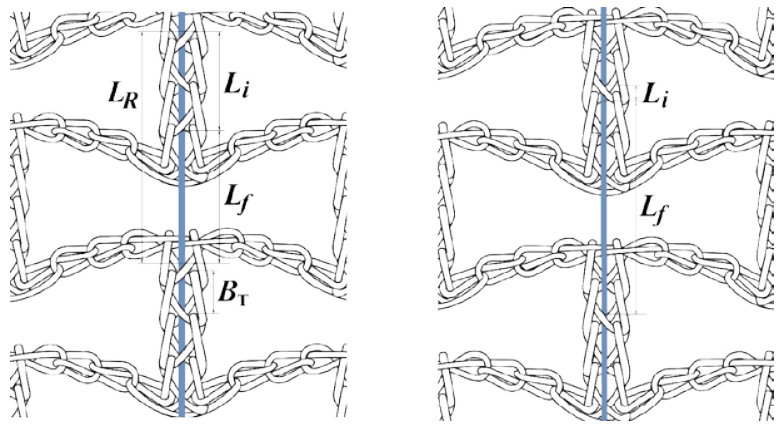

a: Inlaid yarn in contact with 3 courses

b: Inlaid yarn in contact with 1 course

Figure 3: In-laid yarn positions between the tricot junctures from different ground yarns. 
Based on prior presented dependences, the lengths of elastomeric yarn, which are not fixed in the structure, are given as follows:

- $\quad$ length the knitting machine:

$L_{i f}^{s}=\left(2 \mathrm{n}_{\mathrm{t}}-\mathrm{i}+0.5\right) B_{t \max }+2 n_{c} B_{c \max }$

- length needed to achieve auxetic effect after relaxation:

$L i_{f}<\left(2 n_{t}-1.5-i\right) B_{t}-2 b_{2}$

Thus, to achieve the auxetic effect in warp knitted filet structure the elastomeric in-laid yarn must be fed with the prior stretching, , which is determined as follows:

$$
\varepsilon>\left[\frac{\left(2 n_{t}-i+0.5\right) B_{t \max }+2 n_{c} B_{c \max }}{\left(2 n_{t}-1.5-i\right) B_{t}-2 b_{2}}-1\right] 100 \%
$$

It is evident that the strain value decreases with increasing number of tricot courses and decreasing number of chain courses within a repeat of filet interlooping as well as the decreasing number of courses in which the in-laid yarn is fixed within the warp knit structure.

Typical results of calculated theoretical strain value of elastomeric yarn that predict auxetic property of filet net structure are shown at Table 1 . The theoretical Poisson's ratio has been calculated with reference to the relationships derived from Figure 2 as follows:

$$
V_{x y}=-\frac{\left(2 a_{2}-c\right)}{\left(a_{1}-2 b_{2}-h\right)} \quad \frac{h}{c}
$$

It is observed that the value of negative Poisson's ratio increases with the number of tricot courses as well as chain courses of the interlooping repeat. Thus, the best auxetic property of the filet warp knit is expected for the structure formed by alternation of 7 tricot and 3 chain courses at repeat, but prior stretching of elastomeric yarn should be increased.

\section{Experimental}

\section{Production of Auxetic Fabrics}

In order to verify the auxetic behavior of the model, nine different filet warp knit fabrics with in-lay yarn that is fixed in two courses of repeat as shown in Table 2 were produced. These fabrics were made on a 10 gauge Jakob Muller crochet knitting machine with one needle bed. The warp knit fabrics were made from 250 denier polyester yarn as ground. The 150 denier (96 filaments) polyester yarn covered with one end of 70 denier spandex was used to achieve a high elastic inlay component. Elastomeric yarn was fed into the knitting zone with elongation of $150 \%$ [21]. This elastomeric yarn is in-laid between the stitch wale in the knitting direction to ensure that the fabric structure retains the necessary configuration after relaxation.

\section{Measurement of some fabric physical properties}

A description of each measured property is given below:

Courses per unit length and Wales per unit length: A course is a predominantly horizontal row of loops produced by adjacent needles during the same knitting cycle. In warp knitting each loop in a course normally is composed of a separate yarn. Courses per inch (cpi) or courses per $\mathrm{cm}$ are used to evaluate the loops along the axial or walewise direction. A wale is a predominantly vertical column of needle loops produced by the same needle knitting at successive knitting cycles and thus intermeshing each new loop through the previous loop. In warp knitting a wale can be produced from the same yarn. Wales per inch (wpi) or wales per $\mathrm{cm}$ are used to evaluate the loops along the

\begin{tabular}{|c|c|c|c|c|c|c|}
\hline \multirow{2}{*}{$\begin{array}{c}\text { Sample } \\
\text { Designation }\end{array}$} & \multicolumn{2}{|c|}{$\begin{array}{l}\text { Number of courses at } \\
\text { interlooping repeat }\end{array}$} & \multicolumn{3}{|c|}{$\begin{array}{l}\text { Minimum strain value } \varepsilon \text { for different } \\
\text { positions of in-laid yarn, } \%\end{array}$} & \multirow{2}{*}{$\begin{array}{c}\text { Poisson's ratio, } \\
\text { vxy }\end{array}$} \\
\hline & Tricot, $\mathrm{n}_{\mathrm{t}}$ & chain $n_{c}$ & $\mathrm{i}=1$ & $i=2$ & $i=3$ & \\
\hline AX3-1 & 3 & 1 & 483 & 947 & - & -0.031 \\
\hline AX3-2 & 3 & 2 & 614 & 1222 & - & -0.130 \\
\hline AX3-3 & 3 & 3 & 746 & 1497 & - & -0.196 \\
\hline AX5-1 & 5 & 1 & 198 & 226 & 270 & -0.144 \\
\hline AX5-2 & 5 & 2 & 240 & 278 & 334 & -0.698 \\
\hline AX5-3 & 5 & 3 & 283 & 329 & 399 & -1.070 \\
\hline AX7-1 & 7 & 1 & 143 & 152 & 164 & -0.195 \\
\hline AX7-2 & 7 & 2 & 168 & 181 & 196 & -1.179 \\
\hline AX7-3 & 7 & 3 & 194 & 209 & 228 & -1.846 \\
\hline
\end{tabular}
transverse or coursewise direction. The number of courses and the

\begin{tabular}{|c|c|c|c|c|c|c|c|}
\hline \multirow{3}{*}{$\begin{array}{l}\text { Sample } \\
\text { Designation }\end{array}$} & \multicolumn{2}{|c|}{$\begin{array}{c}\text { Number of courses at interlooping } \\
\text { repeat }\end{array}$} & \multicolumn{2}{|c|}{ Number of loops per $\mathrm{cm}$} & \multirow{3}{*}{$\begin{array}{c}\text { Stitch } \\
\text { Loops } \\
\text { per } \mathrm{cm}^{2}\end{array}$} & \multirow{3}{*}{$\begin{array}{c}\text { Basis weight, } \\
\text { g/sq.m }\end{array}$} & \multirow{3}{*}{ Thickness mm } \\
\hline & \multirow{2}{*}{ tricot, $\mathrm{n}_{\mathrm{t}}$} & \multirow{2}{*}{ chain, $\mathrm{n}_{\mathrm{c}}$} & Wales & Courses & & & \\
\hline & & & $\mathbf{N}_{\mathrm{w}}$ & $\mathrm{N}_{\mathrm{c}}$ & & & \\
\hline AX3-1 & 3 & 1 & 3.9 & 21.2 & 82.7 & 283.2 & 0.97 \\
\hline AX3-2 & 3 & 2 & 3.5 & 23.0 & 80.5 & 254.7 & 1.06 \\
\hline AX3-3 & 3 & 3 & 3.3 & 27.0 & 89.1 & 244.9 & 1.09 \\
\hline$A \times 5-1$ & 5 & 1 & 4.0 & 23.2 & 92.8 & 289.6 & 1.08 \\
\hline$A \times 5-2$ & 5 & 2 & 3.7 & 24.0 & 88.8 & 261.6 & 1.16 \\
\hline AX5-3 & 5 & 3 & 3.3 & 27.7 & 91.4 & 253.1 & 1.07 \\
\hline$A \times 7-1$ & 7 & 1 & 4.0 & 23.7 & 94.8 & 293.4 & 1.15 \\
\hline$A \times 7-2$ & 7 & 2 & 3.7 & 25.5 & 94.4 & 285.7 & 1.32 \\
\hline AX7-3 & 7 & 3 & 3.3 & 29.1 & 96.0 & 264.8 & 1.26 \\
\hline
\end{tabular}

Table 1: Theoretical strain values of elastomeric yarn.

Table 2: Structural parameters of auxetic warp knit fabrics 


\begin{tabular}{|c|c|c|c|c|c|c|}
\hline \multicolumn{5}{|c|}{ Unit size, $\mathrm{mm}$} & \multirow{2}{*}{\multicolumn{2}{|c|}{$\begin{array}{l}\text { Poisson's ratio } v_{x y} \text { at } \\
\text { various strain levels }\end{array}$}} \\
\hline \multirow[t]{2}{*}{$\begin{array}{c}\text { Sample } \\
\text { Designation }\end{array}$} & \multirow[t]{2}{*}{$\begin{array}{l}\text { Length of } \\
\text { vertical rib } a_{1}\end{array}$} & \multirow[t]{2}{*}{$\begin{array}{l}\text { Length of diagonal } \\
\qquad \text { rib } a_{2}\end{array}$} & \multicolumn{2}{|c|}{$\begin{array}{l}\text { Distance between two } \\
\text { vertical ribs }\end{array}$} & & \\
\hline & & & $\begin{array}{l}\text { in walewise } \\
\text { direction } \mathrm{h}\end{array}$ & $\begin{array}{l}\text { in coursewise } \\
\text { direction c }\end{array}$ & $10 \%$ & $30 \%$ \\
\hline AX3-1 & 3.76 & 1.94 & 2.01 & 6.31 & 0.003 & 0.052 \\
\hline AX3-2 & 4.07 & 2.52 & 2.12 & 7.49 & -0.022 & 0.038 \\
\hline AX3-3 & 3.13 & 4.80 & 4.53 & 8.57 & -0.062 & 0.011 \\
\hline$A \times 5-1$ & 5.26 & 1.71 & 3.69 & 5.94 & -0.034 & 0.068 \\
\hline$A \times 5-2$ & 5.19 & 2.56 & 5.28 & 6.54 & -0.076 & -0.016 \\
\hline AX5-3 & 5.48 & 4.29 & 5.26 & 8.14 & -0.082 & -0.004 \\
\hline$A \times 7-1$ & 5.46 & 1.90 & 5.73 & 7.02 & -0.108 & -0.094 \\
\hline AX7-2 & 5.26 & 2.41 & 6.29 & 7.75 & -0.143 & -0.073 \\
\hline AX7-3 & 6.09 & 3.47 & 5.82 & 8.86 & -0.162 & -0.024 \\
\hline
\end{tabular}

Table 3: Analysis of unit cell geometry and Poisson's Ratio of fabrics.

number of wales per unit length are obtained by using a counting glass. The results are reported using SI units namely, number of courses or wales in $10 \mathrm{~mm}$. The mean of ten readings is recorded for each direction of the fabric.

Stitch density, S: The term loop or stitch density, S, is the total number of needle loops in a square area measurement. It is obtained by multiplying, for instance, the number of courses and wales, per square unit length together. The unit is loops $/ \mathrm{in}^{2}$ or loops per $\mathrm{cm}^{2}$.

Thickness and basis weight: The thickness (with the unit of $\mathrm{mm}$ ) of each sample is tested using a Thickness Testing Instrument according to ASTM D1777-64.8. Each sample is also weighed on an electronic balance to determine its basis weight or areal density $\left(\mathrm{g} / \mathrm{m}^{2}\right)$.

Measurement of Poisson's ratio: To measure the Poisson's ratio of the identified fabrics, video-extensometry along with micro-tensile testing techniques are employed by using Instron 5569 Mechanical Tester ASTMD5034-95 (2001). All samples are tested by straining the entire fabric strip evenly and each duly marked $2 \mathrm{~cm} \times 2 \mathrm{~cm}$ square of the sample is measured to obtain the Poisson's ratio by using the equation, $v_{\mathrm{xy}}=-\varepsilon_{\mathrm{x}} / \varepsilon_{\mathrm{y}}$ where $\varepsilon_{\mathrm{x}}$ is the strain in the $\mathrm{x}$-direction, or transverse strain, and $\varepsilon_{\mathrm{y}}$ is the strain in the $\mathrm{y}$-direction, or the axial strain. Initially all samples of $10 \mathrm{~cm}$ long are strained at a rate of $5.08 \mathrm{~cm} / \mathrm{min}$, in the walewise and coursewise directions. The test process is observed with a Canon Pro 300 camera. The strain of the sample is measured using the camera to capture an image of the sample at different strain levels, totaling 16 pictures per sample. The width of each sample is measured in three locations to insure that the measured Poisson's ratio is as accurate of measurement as possible [22]. Each fabric structure is tested three times, using different samples of the fabric structure each test. The Poisson's ratio is obtained after all samples had been photographed and strain values obtained using appropriate image analysis software. It should be noted in the photographs that the relationship of interest (for determining if auxetic) is not necessarily the relationship of the strain in the $\mathrm{y}$ direction to the $\mathrm{x}$ direction. The axial strain can still be greater than the transverse strain (as pictured), yet the auxetic nature is a reflection of the transverse strain increasing under axial load (as measured, the width of the box increased relative to the initial width). All the samples were tested along the wale direction. Then the Poisson's ratio was calculated using the equation:

$$
V_{x y}=-\varepsilon_{x} / \varepsilon_{\mathrm{y}}
$$

where vxy is Poison's ratio, $\varepsilon_{\mathrm{x}}$ is transverse strain, and $\varepsilon_{\mathrm{y}}$ is axial strain.
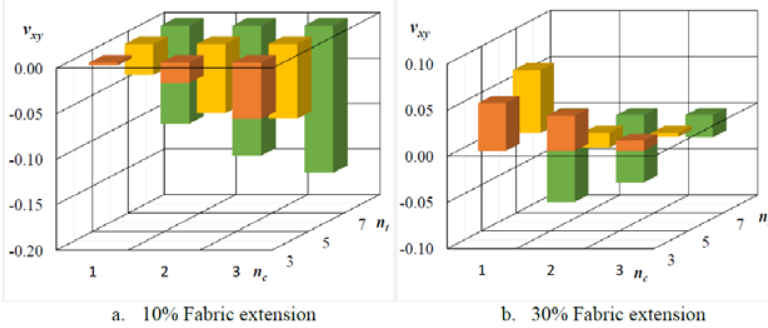

Figure 4: Poissons ratio for auxetic warp knit fabrics

Poisson's ratio is the ratio of transverse contraction strain to longitudinal extension strain in the direction of stretching force.

\section{Results and Discussion}

The structural parameters of the auxetic warp knit fabrics are shown in Table 2. Details of the experimental measurements of unit cell geometry and Poisson's ratio are presented in Table 3. Also, the values of the Poisson's ratio at different strain levels are presented in Figure 4. The measurement of Poisson's ratio is an important fundamental tool for determining the auxetic property of materials. If the Poisson's ratio is negative then the structure is auxetic. Ugbolue et al. [4] have shown that the factor which influences the Poisson's ratio is identified as intrinsic unit size displacement, which depends on chain course numbers. It is surmised that the Poisson's ratio values decrease as the number of tricot courses increase. Indeed, the auxetic properties depend on the interaction of vertical and horizontal ribs in the knitted structure as shown in the model.

As shown in Figure 4, the Poison's ratio of warp knit structures is increasing with increasing number of tricot and chain courses per interlooping repeat. However, such tendency is observed at low strain levels, up to $10 \%$ of fabric stretching. At $30 \%$ fabric extension, only the knit structure with 7 tricot courses as its interlooping repeat has negative Poisson's ratio whose value is shown to decrease with increasing number of chain courses at repeat. The observed low Poisson's ratio effect is attributed to the poor prior (pre-knitting) stretching of the elastomeric in-laid yarn.

\section{Conclusion}

A geometrical analysis of warp knit auxetic fabrics has been 
Citation: Ugbolue SC, Kyzymchuk O, Kim YK T(2015) Geometrical Analysis of Warp Knit Auxetic Fabrics. J Textile Sci Eng 5: 201. doi:10.4172/21658064.1000201

presented in which theoretical computations of the auxetic model were undertaken. Experimental results validate the theoretical computation. Also, it has been established that the experimental values produced lower negative

Poisson's ratios primarily because of the low pre-tensioning of the inlay spandex yarns employed. On the basis of these results, future fabrication of auxetic warp knit structures must employ higher pretensioned $100 \%$ elastomeric inlay yarn in order to improve on the auxetic properties and characteristics of the warp knit auxetic fabrics.

\section{Acknowledgement}

One of the authors, Olena Kyzymchuk, is grateful for the funds provided by the Council for International Exchange of Scholars (CIES) and Institute of International Education (IIE) under the Fulbright Visiting Scholar Program at the Department of Bioengineering, University of Massachusetts, Dartmouth, MA 02747, USA.

\section{References}

1. Alderson A, Alderson K (2005) Expanding materials and applications: exploiting auxetic textiles. Text Int 14: 29-34.

2. Ugbolue SC, Warner SB, Kim YK, Fan Q, Chen Lu, et al. (2010) The Formation and Performance of Auxetic Textiles, Part 1: Theoretical and Technical Considerations, J Text Inst 101: 660-667.

3. Ugbolue SC, Warner SB, Kim YK, Fan Q, Chen Lu, et al. (2011) The Formation and Performance of Auxetic Textiles, Part 1I: Geometry and Structura Properties. J Text Inst 102: 424-433.

4. Liu YP, Hu H, Lam JKC, Su Liu (2010) Negative Poisson's ratio weft-knitted fabrics. Text Res J 80: 856-863.

5. Hu H, Wang ZY, Liu S (2011) Development of auxetic fabrics using flat knitting technology. Text Res J 81: 1493-1502.

6. Alderson K, Alderson A, Anand S, Simkins V, Nazare S, et al. (2012) Auxetic warp knit textile structures, physica status solidi(b) 249: 1322-1329

7. Fletcher HM, Roberts SH (1956) The Geometry and Properties of Two-bar Tricot Fabrics of Acetate, Viscose, and Cotton. Text Res J 31: 151-159.
8. Siimmel R (1951) An Approach to Tricot Fabric Engineering. Text World 101: 130

9. Stimmel R (1952) Standardisation of Tricot Construction. Knit. Outers Times 20: $71-73$

10. Allison GL (1958) Warp-knitting Calculations Made Easy, Skinner's Silk Rayon $\operatorname{Rec} 32: 28 \mathrm{i}-283$

11. Grosberg P (1960) The Geometry of Warp-knitted Fabrics. J Text Inst 51: T39-T48.

12. Grosberg P (1964) The Geometrical Properties of Simple Warp-knit Fabrics. J Text Inst 55: T18-T30.

13. Shinn WE, El-Araf M (1966) The Geometry of Warp-knit Structures, Knit. Outerwears Times 35: 24-27.

14. Wheatley B (1973) The Dimensional Properties of Raschel-knitted Fabrics Constructed from Wool Yams.

15. Goktepe O, Harlock SC (2002) A 3D Loop Model for Visual Simulation of Warpknitted Structures. J Text Inst 93:11-28

16. Kyzymchuk O, Ugbolue SC (2012) The effect of positioning of inlaid yarns in fillet warp knit structures.

17. Dalidovich AS (1970) Basics of knitting technology.

18. Goktepe O, Harlock SC (2002) 3D Computer Modelling of Warp-knitted Structures. Text Res J 72: 266-272

19. Ugbolue SC, Warner SB, Kim YK, Fan Q, Chen Lu, et al. (2006) The Formation and Performance of Auxetic Textiles.

20. Ugbolue SC, Warner SB, Kim YK, Fan Q, Chen Lu, et al. (2007) The Formation and Performance of Auxetic Textiles.

21. Ugbolue SC, Warner SB, Kim YK, Fan Q, Chen Lu, et al. (2008) The Formation and Performance of Auxetic Textiles.

22. Ugbolue SC, Warner SB, Kim YK, Fan Q, Chen Lu, et al. (2009) The Formation and Performance of Auxetic Textiles. 